\title{
Distribution, source apportionment, and health risk assessment of phthalate esters in indoor dust samples across China
}

\author{
Xu Li ${ }^{1,3}$, Wenping Zhang ${ }^{1,3}$, Jiapei Lv ${ }^{1,2,3}$, Wenxiu Liu ${ }^{1,2,3}$, Shanwei Sun ${ }^{1,2,3}$, Changsheng Guo $0^{1,2,3^{*}}$ (D) \\ and Jian $X_{u^{1,2,3}}$
}

\begin{abstract}
Background: Phthalates were detected in various environments due to their widespread application. In this study, indoor dust samples from 94 buildings, including 72 residences and 22 dormitories, were collected in seven geographical regions in China and analyzed for eight phthalate esters (PAEs). Investigation of contamination profiles, geographical distribution, sources, and risks of PAEs in indoor dusts was explored.

Results: The highest $\Sigma_{8}$ PAEs concentration in residential buildings was found in Northeast China (median: $164.71 \mu \mathrm{g} \cdot \mathrm{g}^{-1}$ ), which was 2.3 and 2.8 times higher than that in South China (median: $71.71 \mathrm{\mu g} \cdot \mathrm{g}^{-1}$ ) and Southwest China (median: $58.53 \mathrm{\mu g} \cdot \mathrm{g}^{-1}$ ), respectively. Di (2-ethylhexyl) phthalate (DEHP), di-iso-butyl phthalate (DIBP), and din-butyl phthalate (DBP) were the dominant compounds of $\Sigma_{8}$ PAEs in indoor dusts from residences and dormitories. The administrative levels revealed that the highly serious contamination occurred in the provincial capital, followed by nonprovincial cities and countries. Such an occurrence was related to the usage of PAE products and the level of urbanization. Principal component analysis (PCA) and positive matrix factorization (PMF) showed that the emission from cosmetics and personal care products, plasticizers, and household building materials were the possible PAE sources in indoor dusts. Among three routes of ingestion, dermal adsorption, and inhalation, dust ingestion was the main route of human exposure to PAEs. The health risk of PAE exposure for different populations in descending order of children $>$ women $>$ men. The hazard indexes of noncancer were higher than the threshold value of $10^{-6}$ during human exposure to DBP and DEHP. Children also faced potential noncancer risk due to benzyl butyl phthalate (BBzP) and di-n-octyl phthalate (DnOP) exposure. The carcinogenic risks via exposure to BBzP and DEHP were negligible.
\end{abstract}

Conclusion: Overall, PAEs were widely presented in indoor dusts. Obvious difference was observed in the distribution of PAEs concentration in indoor dusts due to the differences in economic development and usage of PAEs product. Plasticizers, household building materials, and cosmetics and personal care products were likely PAE sources in indoor dusts. The risk assessment suggested that carcinogenic risks of BBzP and DEHP were negligible, but DBP, DEHP, DnOP, and BBzP may pose noncancer risks to humans.

Keywords: Indoor dust, Phthalate esters exposure, Geographical distribution, Sources, Risk assessment

*Correspondence: guocs@craes.org.cn

${ }^{1}$ State Key Laboratory of Environmental Criteria and Risk Assessment, Chinese Research Academy of Environmental Sciences, Beijing 100012, China

Full list of author information is available at the end of the article

\section{Background}

Phthalate esters (PAEs) are a class of manufactured organic chemicals that have been used as plasticizers/ additives, emollients, antifoaming agents, humectants, or carriers in various industrial and consumer products [14]. Phthalate esters were dominated plasticizers, accounting for $70-80 \%$ of the market share of plastic plasticizers, 
and the domestic PVC production capacity was 22.82 million tons in 2017 [5]. From January to September 2019 , the total output of national plastic products industry enterprises has been reached 59.94 million tons [6].

The employment of various phthalates differs widely with chemical and physical properties [7]. Low molecular weight PAEs, such as dimethyl phthalate (DMP), diethyl phthalate (DEP), and di-n-butyl phthalate (DBP), are mainly used as solvents or carriers in personal care products and coatings. DBP is additionally used in cellulose esters, epoxy resins, and special adhesive formulations [1]. Meanwhile, PAEs with long/branching alkyl chain, such as di(2-ethylhexyl) phthalate (DEHP), di-n-octyl phthalate (DnOP), and benzyl butyl phthalate (BBzP), are mainly used as plasticizers in the polymers to improve flexibility, workability, and general handling properties $[1$, 8].

Most PAEs are physically mixed to the polymeric materials, thereby facilitating their easy entrance to the environment during their manufacture, usage, or disposal [4, 9]. The widespread application of products containing PAEs in daily life resulted in their universality in environments and frequent detection in various environmental matrices, including drinking water [10], surface water [11], indoor/outdoor air [12-14], dust [7, 15], sediment $[16,17]$, soil [18, 19], food [20], and urine [21, 22]. Meanwhile, some PAEs [e.g., DEHP, DBP, BBzP, DEP, and di$\mathrm{n}$-hexyl phosphoric acid (DHXP)] have been proven to be endocrine-disrupting compounds, and exposure to phthalates may result in reproductive effects [23], hypertension, and childhood obesity problems [8, 24-26]. Six PAEs, including DMP, DEP, BBzP, DBP, DEHP, and DnOP, have been listed as priority pollutants by the USEPA and the European Union due to their widespread occurrence in the biosphere and potential adverse effects on the environment and humans [27, 28, 29, 29]. DEP, DBP, and DnOP have also been identified as priority pollutants by the National Environmental Monitoring Center in China [30].

Persistent organic pollutants (POPs) tend to accumulate in the dust and soils [31]. Humans spend most of their time indoors; thus, indoor dust is a considerable daily exposure source of PAEs for humans. To date, an increasing number of studies reported the contamination of PAEs in indoor dust in different building environments. However, limited information of PAEs in dust is available. For instance, a few studies investigated the PAEs in different types of indoor dust in the USA [32], Germany [33, 34], Denmark [35], Norway [35, 36], Sweden $[9,37]$, and Japan [38]. As one of the largest PAE producers and users in the world, China has also conducted a few surveys on the occurrence of PAEs in indoor dusts. However, these surveys are limited to localized regions, such as Xi'an [15], Beijing [3], Nanjing [39], Xinjiang [40], and the Pearl River Delta [41]. Children are physiologically more vulnerable to environmental pollution when compared with adults because children are considerably exposed due to their frequent skin contact with PAEcontaining products [42]. Therefore, assessing the health risk from exposure to PAEs in residential dust in China is urgent. Till date, only one study reported a nationwide survey on the characteristics of PAEs in indoor dust collected from bedrooms or saloons in China. However, this study only estimated the daily intake (DI) via various routes, and the exposure risks were not assessed [43]. In this study, eight PAEs were analyzed in 94 indoor dust samples collected across China. This study aims to investigate the concentration, spatial distribution characteristics, sources, and health risks to human (including noncancer and carcinogenic risks) exposure to PAEs in indoor dusts from residences and dormitories.

\section{Materials and methods Standards}

Eight PAE standards (DMP, DBP, DEP, DIBP, BBzP, DEHP, DnOP, and dinonyl phthalate (DNP)) were obtained from AccuStand (New Haven, CT, USA), and their structures and selected physicochemical properties were summarized in Additional file 1: Table S1. The deuterated internal standards of diethyl phthalate-3,4,5,6- $\mathrm{d}_{4}\left(\right.$ DMP- $\mathrm{d}_{4}$, $\left.0.10 \mathrm{~g} \cdot \mathrm{mL}^{-1}\right)$, di-n-butyl phthalate- $\mathrm{d}_{4}\left(\mathrm{DBP}-\mathrm{d}_{4}\right)$, and bis (2-ethylhexyl) phthalate-3,4,5,6- $\mathrm{d}_{4}\left(\mathrm{DEHP}-\mathrm{d}_{4}\right)$ were purchased from AccuStand. Acetone and ethyl acetate used were chromatographically pure and purchased from Burdick \& Jackson.

\section{Sample collection and preparation}

The collection of 94 dust samples, including 72 bedroom or drawing room dust samples from houses and 22 dust samples from dormitories, was conducted from seven regions in China during August and October 2019. Detailed information on all sampling sites is presented in Additional file 1: Figure S1. Before sampling, the floor to be sampled is cleaned by owners. Dust samples were collected by gently sweeping the top of furniture and the floor with disposable brushes. All brushes used before sampling were precleaned with methanol. After sampling, the samples were wrapped with aluminum foils and stored in a polyethylene zip-lock bag. Then, the samples were transported to the laboratory within three days. Subsequently, dusts were sieved through a 200mesh sieve, homogenized thoroughly, and then stored in a brown glass jar at $4{ }^{\circ} \mathrm{C}$ until analysis. All samples were analyzed within $30 \mathrm{~d}$. 


\section{Sample analysis}

Indoor dust samples $(0.10 \mathrm{~g}$, dry weight $)$ were put into a $15 \mathrm{~mL}$ glass tube, and $200 \mathrm{ng}$ internal standards were spiked to the samples. PAEs in dust samples were extracted with $2 \mathrm{~mL}$ ethyl acetate by mechanical oscillation at $180 \mathrm{rpm}$ for $1 \mathrm{~h}$ and left at room temperature for $1 \mathrm{~h}$. Approximately $1 \mathrm{~mL}$ of extract was transferred to a $\mathrm{GC}$ vial. The extraction method consulted the standard "Soil quality -Determination of selected phthalates using capillary gas chromatography with mass spectrometric detection (GC/MS)" (ISO 13913-2014) [44].

\section{Instrumental analysis}

The extracts were analyzed with a Shimadzu gas chromatography-mass spectrometry (GCMS-QP2010Plus, Shimadzu, Japan) equipped with an electron ionization (EI) source. Quantification of each target compound was performed in the single ion monitoring (SIM) mode. The analytes were separated using a capillary column (DB-5MS, $30 \mathrm{~m} \times 0.25 \mathrm{~mm} \times 0.25 \mu \mathrm{m}$ ). The flow rate of the ultra-high purity helium carrier gas (purity 99.999\%) was maintained at $1.0 \mathrm{~mL} \cdot \mathrm{min}^{-1}$. The column temperature program started at $60{ }^{\circ} \mathrm{C}$ (held for $1.0 \mathrm{~min}$ ), ramped to $220^{\circ} \mathrm{C}$ at a rate of $20{ }^{\circ} \mathrm{C} \cdot \mathrm{min}^{-1}$ and held for $1.0 \mathrm{~min}$, and finally increased at $5{ }^{\circ} \mathrm{C} \cdot \mathrm{min}^{-1}$ to $290^{\circ} \mathrm{C}$ and held for $9.0 \mathrm{~min}$. The ion source, injection port, and quadrupole, and transmission line temperatures were maintained at 300,300 , and $250{ }^{\circ} \mathrm{C}$, respectively. The injection volume was $1 \mu \mathrm{L}$. Quantification was conducted by the external calibration method based on a six-point calibration curve for each compound.

\section{Quality assurance and quality control (QA/QC)}

All kinds of plastic containers were strictly avoided to reduce background contamination during the entire sample processing. All glassware was precleaned three times with acetone before use. The calibration curves were measured for all eight PAEs with concentrations ranging from $20 \mathrm{ng} \cdot \mathrm{mL}^{-1}$ to $1000 \mathrm{ng} \cdot \mathrm{mL}^{-1}$, and the regression coefficients of calibration curves were $>0.99$. The LODs of PAEs ranged from $0.0008 \mu \mathrm{g} \cdot \mathrm{g}^{-1}$ for DBP to $0.0048 \mu \mathrm{g} \cdot \mathrm{g}^{-1}$ for DnOP. The LOQs for DMP, DEP, DIBP, DBP, BBzP, DEHP, DnOP, and DNP were 0.0038, 0.0098, $0.0027,0.0024,0.0128,0.0036,0.0143$, and $0.0095 \mu \mathrm{g} \cdot \mathrm{g}^{-1}$, respectively (Additional file 1: Table S2). Blank samples were processed with every batch of 20 samples. No target compound was detected in procedural blanks; therefore, the background concentration of these chemicals was neglected. The relative recoveries of target PAEs in spiked matrix samples ranged from 75.95 to $125.36 \%$, while those of internal standards in spiked blank mats, spiked matrices, and dust samples were $80.34-131.61 \%$,
$76.54-116.86 \%$, and $76.89-120.98 \%$, respectively. The precision of the analytical method was evaluated by randomly selecting 10 samples analyzed in duplicate, with the coefficient variation below $15 \%$.

\section{Statistical analysis}

Statistical analysis was conducted with IBM SPSS Statistics 25.0, EPA PMF 5.0, and Origin 2019. A spatial distribution map of PAEs was created using ArcGIS version 10.2. Concentrations lower than the LOQ were assigned a value of LOQ/2 for statistical analysis. Pearson's correlation was employed to analyze correlations between PAE concentrations in various environmental matrices. PCA and PMF receptor models used in this study are widely used factor analysis receptor models which do not need source profiles. The explicit descriptions of these models can be found in our previous studies [45-47]. They are also provided in the supplementary information. Generally, they can be expressed by the following basic Eq. (1):

$$
x_{i k}=\sum_{j=1}^{p} g_{i p} f_{p k}+e_{i k}
$$

where $x_{i k}$ is the concentration of $i$ th species for the $k$ th sample; $f_{p k}$ is the contribution of the $p$ th source to the $k$ th sample; $g_{i p}$ is the $i$ th species concentration from the $p$ th source; and $e_{i k}$ is the error. Factors extracted from the ambient concentrations can be linked to potential source categories.

\section{Human exposure and health risk assessment}

The formulas with slight modification from the US EPA [48], which have been widely employed in previous studies [27, 43, 49], are defined as Eqs. (2-4) to assess the average daily dosage (ADD, mg. $\mathrm{mg} \cdot \mathrm{kg}^{-1} \cdot \mathrm{d}^{-1}$ ) of PAEs for adults and children via different exposure pathways of PAEs, namely ingestion, dermal absorption, and inhalation. $\mathrm{ADD}_{\text {ing }}, \mathrm{ADD}_{\text {der }}$, and $\mathrm{ADD}_{\text {inh }}$ are the $\mathrm{ADD}$ $\left(\mathrm{mg} \cdot \mathrm{kg}^{-1} \cdot \mathrm{d}^{-1}\right)$ through dust ingestion, dermal absorption, and inhalation, respectively.

$$
\begin{aligned}
& \mathrm{ADD}_{\text {ing }}=\frac{\mathrm{C}_{\text {dust }} \times \mathrm{IR}_{\text {ingestion }} \times \mathrm{EF} \times \mathrm{ED} \times \mathrm{CF}}{\mathrm{BW} \times \mathrm{AT}} \\
& \mathrm{ADD}_{\text {der }}=\frac{\mathrm{C}_{\text {dust }} \times \mathrm{SA} \times \mathrm{AF} \times \mathrm{ABF} \times \mathrm{EF} \times \mathrm{ED} \times \mathrm{CF}}{\mathrm{BW} \times \mathrm{AT}} \\
& \mathrm{ADD}_{\text {inh }}=\frac{\mathrm{C}_{\text {dust }} \times \mathrm{IR}_{\text {inhalation }} \times \mathrm{EF} \times \mathrm{ED}}{\mathrm{BW} \times \mathrm{AT} \times \mathrm{PEF}}
\end{aligned}
$$

where $C_{\text {dust }}$ is the PAE concentration measured in dust $\left(\mathrm{mg} \cdot \mathrm{kg}^{-1}\right) . \mathrm{IR}_{\text {ingestion }}$ is the dust ingestion rate $\left(\mathrm{mg} \cdot \mathrm{d}^{-1}\right)$.

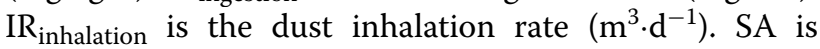


the dermal exposure area $\left(\mathrm{cm}^{2}\right)$. ABF is the dermal adsorption fraction. AF is the dermal adherence factor for dust $\left(\mathrm{mg} \cdot \mathrm{cm}^{-2} \cdot \mathrm{d}^{-1}\right)$. BW is the body weight $(\mathrm{kg})$. AT is the averaging time (d): for noncancer risks, AT $(\mathrm{d})=\mathrm{ED} \times 365$; for carcinogens risks, AT $(\mathrm{d})=$ average lifetime $\times 365$. ED is the exposure duration (y). EF is the exposure frequency $\left(\mathrm{d} \cdot \mathrm{y}^{-1}\right)$. CF is the conversion factor $\left(1.0 \times 10^{-6} \mathrm{~kg} \cdot \mathrm{mg}^{-1}\right)$. PEF is the particle emission factor $\left(1.36 \times 10^{9} \mathrm{~m}^{3} \cdot \mathrm{kg}^{-1}\right)$.

Carcinogenic and noncancer risks of PAEs were assessed following the procedures by the US EPA (2001) [48]. Noncancer risks of PAE exposure via dust were quantified by the hazard quotient (HQ) and hazard index (HI) using Eqs. (5-6):

$$
\begin{aligned}
& \mathrm{HQ}_{\mathrm{i}}=\frac{\mathrm{ADD}_{\mathrm{i}}}{\mathrm{RfD}} \\
& \mathrm{HI}=\sum \mathrm{HQ}_{\mathrm{i}}
\end{aligned}
$$

where RfD is the reference dose value of each PAE $\left(\mathrm{mg} \cdot \mathrm{kg}^{-1} \cdot \mathrm{d}^{-1}\right)$, HQ represents the health risks of the individual PAEs to human health via different exposure routes, and i represents different exposure routes. The values of $\mathrm{HI}>1 \times 10^{-6}$ indicate that the exposure of inhabitants to PAEs might induce the noncancer risk.

As for the carcinogenic PAEs, the lifetime average daily exposure doses (LADD, $\mathrm{mg} \cdot \mathrm{kg}^{-1} \cdot \mathrm{d}^{-1}$ ) were estimated on the basis of the following expressions (7-9): risk. The relevant parameters for human exposure and health risk assessment are listed in Additional file 1: Table S3.

\section{Results and discussion}

\section{Concentrations and spatial distribution of PAEs in indoor dust}

The concentration and detection frequency of PAEs in indoor dusts from residences and dormitories are respectively shown in Fig. 1 and Additional file 1: Figure S2. All eight PAEs were detected in indoor dusts samples, demonstrating a detection frequency from 77.27 to $100 \%$. DMP, DEP, DIBP, DEHP, and DBP were the most frequently detected compounds in all 94 samples, followed by BBzP, DnOP, and DNP in residences with the detection frequency of $81.94-95.83 \%$. Similarly, the detection frequencies of $\mathrm{BBzP}$ and $\mathrm{DnOP}$ in the dormitories were 77.27 and $86.36 \%$, respectively.

The concentrations of the total PAEs ( $\left.\Sigma_{8} \mathrm{PAEs}\right)$ in indoor dusts from residential buildings ranged from $8.86 \mu \mathrm{g} \cdot \mathrm{g}^{-1}$ to $808.43 \mu \mathrm{g} \cdot \mathrm{g}^{-1}$ with a median of $104.58 \mu \mathrm{g} \cdot \mathrm{g}^{-1}$ and a geometric mean of $101.32 \mu \mathrm{g} \cdot \mathrm{g}^{-1}$. The spatial distribution of $\Sigma_{8}$ PAEs is depicted in Fig. 2. Different concentrations were observed in the distribution of PAE concentration in indoor dusts among seven administrative regions of China. The highest concentration of $\Sigma_{8}$ PAEs in indoor dusts was found from Northeast China (NEC, median: $164.71 \mu \mathrm{g} \cdot \mathrm{g}^{-1}$, range: $\left.32.29-778.54 \mu \mathrm{g} \cdot \mathrm{g}^{-1}\right)$. Meanwhile, the relatively low values of $\Sigma_{8}$ PAEs were from North-

$$
\begin{aligned}
& \mathrm{LADD}_{\text {der }}=\frac{\mathrm{C}_{\text {dust }} \times \mathrm{ABF} \times \mathrm{CF}}{\mathrm{AT}}\left(\frac{\mathrm{SA}_{\text {child }} \times \mathrm{AF}_{\text {child }} \times \mathrm{ED}_{\text {child }} \times \mathrm{EF}_{\text {child }}}{\mathrm{BW}_{\text {child }}}+\frac{\mathrm{SA}_{\text {adult }} \times \mathrm{AF}_{\text {adult }} \times \mathrm{ED}_{\text {adult }} \times \mathrm{EF}_{\text {adult }}}{\mathrm{BW}_{\text {adult }}}\right)
\end{aligned}
$$

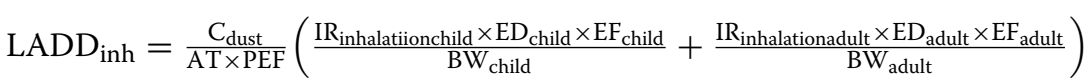

$$
\begin{aligned}
& \mathrm{LADD}_{\text {ing }}=\frac{\mathrm{C}_{\text {dust }} \times \mathrm{CF}}{\mathrm{AT}}\left(\frac{\mathrm{IR}_{\text {ingestionchild }} \times \mathrm{ED}_{\text {child }} \times \mathrm{EF}_{\text {child }}}{\mathrm{BW}_{\text {child }}}+\frac{\mathrm{IR}_{\text {ingestionadult }} \times \mathrm{ED}_{\text {adult }} \times \mathrm{EF}_{\text {adult }}}{\mathrm{BW}_{\text {adult }}}\right)
\end{aligned}
$$

Carcinogenic risk (CR) was obtained from Eq. (10).

$$
\mathrm{CR}=\mathrm{LADD} \times \mathrm{CSF}
$$

where CSF represents the cancer slope factor, including ingestion cancer slope factor ( $\left.\mathrm{CSF}_{\text {ingestion}}\right)$, inhalation cancer slope factor $\left(\mathrm{CSF}_{\text {inhalation }}\right)$, and dermal adsorption cancer slope factor $\left(\mathrm{CSF}_{\text {dermal }}\right)$. $\mathrm{CSF}_{\text {ingestion }}$ is 0.0019 and $0.014 \mathrm{~kg} \cdot \mathrm{d} \cdot \mathrm{mg}^{-1}$ for BBzP and DEHP, respectively $[27,50]$. CSF ${ }_{\text {inhalation }}$ and $\operatorname{CSF}_{\text {dermal }}$ were assumed to be equal to $\mathrm{CSF}_{\text {ingestion }}$ to assess the cancer risks by dermal adsorption and inhalation [27]. A CR value below $1 \times 10^{-6}$ represents the negligible or acceptable cancer west (NWC, median: $145.11 \mu \mathrm{g} \cdot \mathrm{g}^{-1}$, range: $16.88-$ $534.65 \mu \mathrm{g} \cdot \mathrm{g}^{-1}$ ), East China (EC, median: $107.59 \mu \mathrm{g} \cdot \mathrm{g}^{-1}$, range: $32.91-808.43 \mu \mathrm{g} \cdot \mathrm{g}^{-1}$ ), North China (NC, median: $82.60 \mu \mathrm{g} \cdot \mathrm{g}^{-1}$, range: $\left.38.46-416.66 \mu \mathrm{g} \cdot \mathrm{g}^{-1}\right)$, Central China (CC, median: $80.97 \mu \mathrm{g} \cdot \mathrm{g}^{-1}$, range: $8.86-618.62 \mu \mathrm{g} \cdot \mathrm{g}^{-1}$ ), and South China (SC, median: $71.72 \mu \mathrm{g} \cdot \mathrm{g}^{-1}$, range: 25.04-185.32 $\left.\mu \mathrm{g} \cdot \mathrm{g}^{-1}\right)$. The lowest value of $\Sigma$ PAEs in dust was found in Southwest China (SWC, median: $58.83 \mu \mathrm{g} \cdot \mathrm{g}^{-1}$, range: $43.57-266.68 \mu \mathrm{g} \cdot \mathrm{g}^{-1}$ ). On the whole, the concentration of PAEs in northern China was higher than that in southern China. The result was consistent with early studies [43], which was caused by the 
differences in usage patterns between eight PAEs among the seven geographic regions in China.

When considering the individual phthalates in indoor dust among all geographical regions, the composition with the highest concentration in indoor dusts from residential buildings was DEHP, which ranged from $5.60 \mu \mathrm{g} \cdot \mathrm{g}^{-1}$ to $754.41 \mu \mathrm{g} \cdot \mathrm{g}^{-1}$ with a median value of $50.79 \mu \mathrm{g} \cdot \mathrm{g}^{-1}$, followed by DBP (median: $23.56 \mu \mathrm{g} \cdot \mathrm{g}^{-1}$ ) and DIBP (median: $8.84 \mu \mathrm{g} \cdot \mathrm{g}^{-1}$ ). DBP and DEHP are known as the main additives used in the industrial production [51]. Moreover, DBP and DIBP showed a relatively high abundance in indoor dust, which might be related to the extensive usage of DBP and DIBP as personal care products, such as cosmetics and pharmaceutical coatings [29, $29,41]$.

The median concentrations of DEP, DMP, DNP, DnOP, and $\mathrm{BBzP}$ were two orders of magnitude lower than DEHP. Consistent with the results by other studies, the median concentrations of DEP and DMP were generally measured at lower levels than other PAEs in indoor dusts. This measurement was probably due to the high volatility and the reported existence of DEP mainly in gas phase than that in dust phase because of its high vapor pressure and low molecular weight $[9,49,52]$.
A comparison of PAE concentrations in indoor dusts in different regions worldwide is presented in Additional file 1: Table S4. DEHP, DBP, DEP, DMP, and DIBP were the most commonly reported ones. The PAE concentrations (except for DMP and DIBP) detected in this study were slightly higher than those in a previous nationwide survey on the PAE levels in the indoor dust samples in China [43]. DEHP dominated the phthalates contaminating Chinese indoor dusts consistent with the profile in many countries worldwide, but DEHP levels measured in this study were significantly lower than other studies all over the world (Additional file 1: Table S4). The sequence of concentrations of major individual PAEs with DEHP $>$ DBP $>$ DIBP was in agreement with previous reports in China [43], Albany/USA [32], Sweden [9], and France [53]. The DBP concentration in indoor dusts in China $\left(23.56 \mu \mathrm{g} \cdot \mathrm{g}^{-1}\right)$ was lower than that in Sweden $\left(38.00 \mu \mathrm{g} \cdot \mathrm{g}^{-1}\right)$ [9], Saudi Arabia $\left(33.00 \mu \mathrm{g} \cdot \mathrm{g}^{-1}\right)$ [54] and at higher levels than Albany/ USA $\left(13.10 \mu \mathrm{g} \cdot \mathrm{g}^{-1}\right)$ [32], Delaware/USA $\left(12.00 \mu \mathrm{g} \cdot \mathrm{g}^{-1}\right)$ [55], California/USA $\left(18.20 \mu \mathrm{g} \cdot \mathrm{g}^{-1}\right)$ [56], France $\left(9.10 \mu \mathrm{g} \cdot \mathrm{g}^{-1}\right)$ [53], Canada $\left(16.80 \mu \mathrm{g} \cdot \mathrm{g}^{-1}\right)$ [57], and Kuwait $\left(2.00 \mu \mathrm{g} \cdot \mathrm{g}^{-1}\right)$ [54]. The DIBP levels in indoor dusts measured in this study were similar to those in some European countries, such as Sweden with a mean 


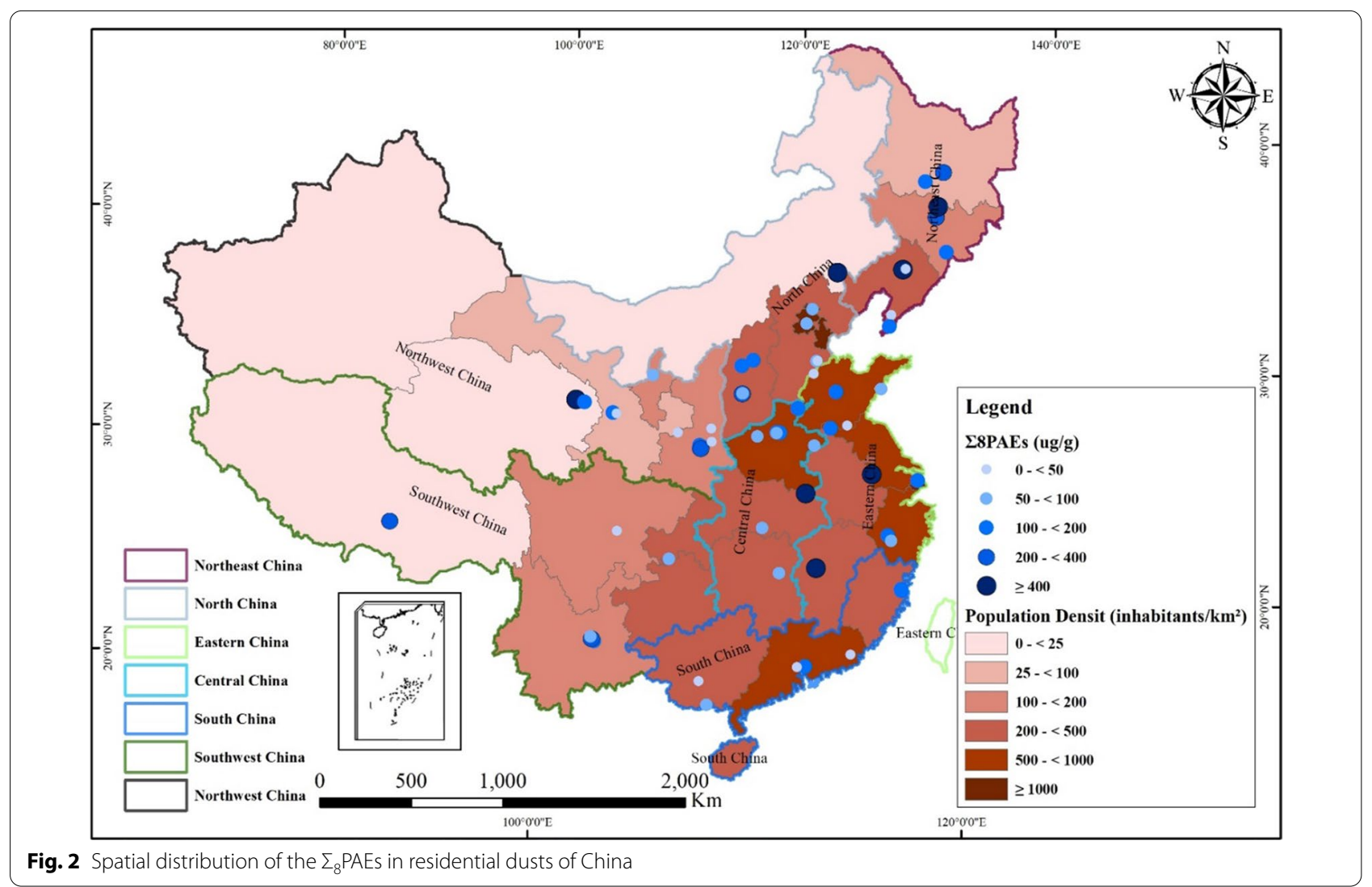

value of $7.90 \mu \mathrm{g} \cdot \mathrm{g}^{-1}[9]$, Belgium at $9.40 \mu \mathrm{g} \cdot \mathrm{g}^{-1}[58]$, and Ireland at $7.00 \mu \mathrm{g} \cdot \mathrm{g}^{-1}[58]$, while lower than those from Saudi Arabia (22.00 $\left.\mu \mathrm{g} \cdot \mathrm{g}^{-1}\right)$ [54], Kuwait $\left(17.00 \mu \mathrm{g} \cdot \mathrm{g}^{-1}\right)$ [54], and France $\left(20.00 \mu \mathrm{g} \cdot \mathrm{g}^{-1}\right)$ [53]. The difference in the compositional profile of PAEs in indoor dust worldwide might be attributed to the difference in housing environment, sampling time, utilization of phthalates in consumer products, and analytical techniques.

The concentrations of $\Sigma_{8} \mathrm{PAEs}$ in dormitories were $14.03-1877.37 \mu \mathrm{g} \cdot \mathrm{g}^{-1}$ with a median value of $55.32 \mu \mathrm{g} \cdot \mathrm{g}^{-1}$. The highest level of individual PAEs in dormitories was DEHP with a median value of $34.65 \mu \mathrm{g} \cdot \mathrm{g}^{-1}$, which was 2.85 and 3.84 times higher than DBP (12.17 $\left.\mu \mathrm{g} \cdot \mathrm{g}^{-1}\right)$ and DIBP (9.02 $\left.\mu \mathrm{g} \cdot \mathrm{g}^{-1}\right)$, respectively.

A comparative analysis of the median concentration of eight phthalate esters in dust in dormitories and residences is shown in Figs. 1 and 3. Thus, the PAE concentration in residences was higher than that in dormitories, except for DIBP. The difference between phthalate concentration in dust in residences and dormitories was likely due to the excessive use of decorative materials, household appliances, and furniture in residential buildings when compared with dormitories.

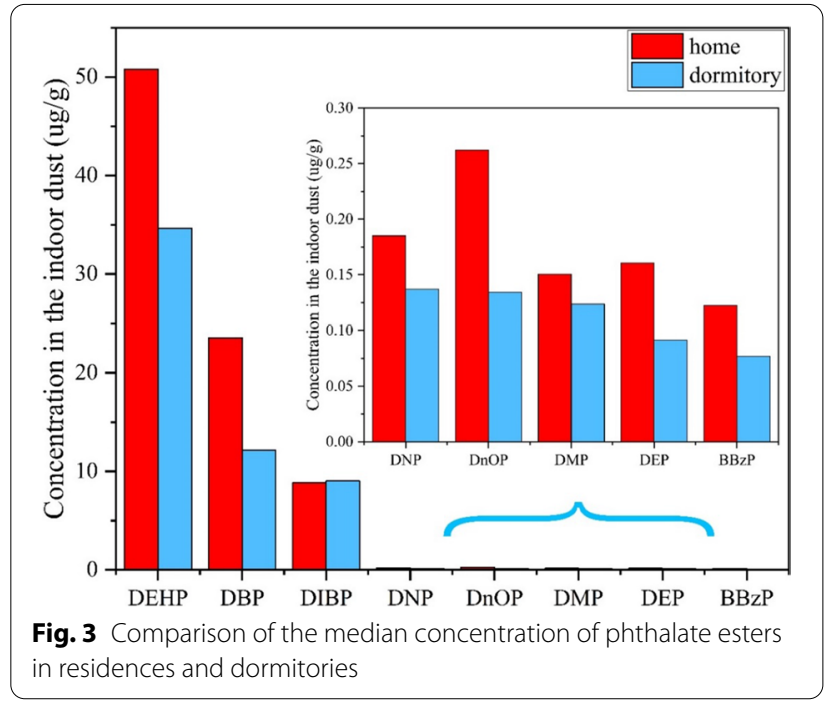

\section{Distribution of PAEs in regions with different} administrative levels

According to the administrative levels, the sampling regions of 72 residential dusts were divided into the following three types: provincial capital, nonprovincial city, and county. Environmental pollution is closely 


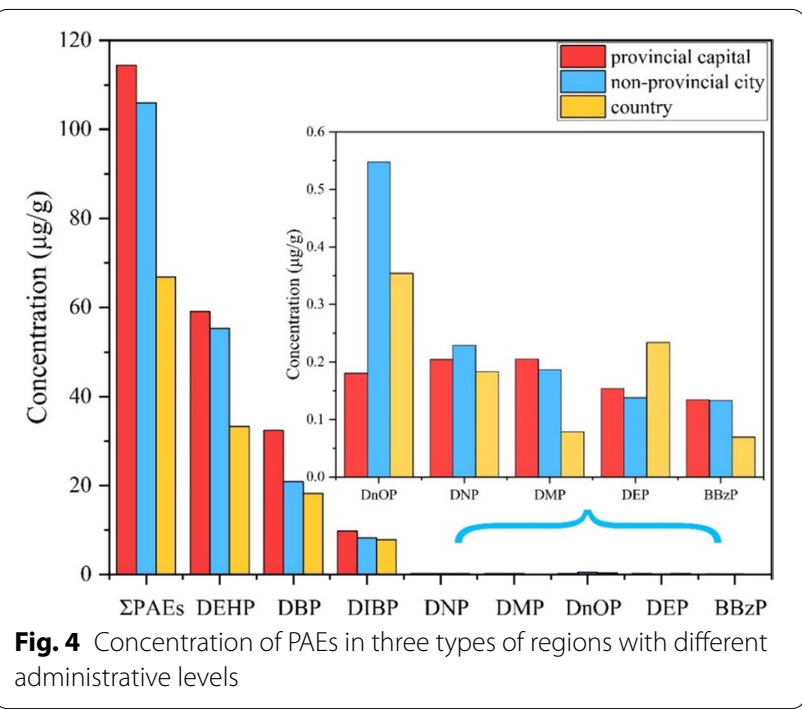

associated with the economic development and urbanization; thus, different degrees of environmental pollution are found in the three types of regions. As shown in Fig. 4, the concentrations of $\Sigma_{8}$ PAEs descended in the order of provincial capital $\left(114.44 \mu \mathrm{g} \cdot \mathrm{g}^{-1}\right)>$ nonprovincial city $\left(105.96 \mu \mathrm{g} \cdot \mathrm{g}^{-1}\right)>$ county $\left(66.83 \mu \mathrm{g} \cdot \mathrm{g}^{-1}\right)$. Up to now, the concentration of PAEs in urban and rural indoor dust has not been discussed. Zhu et al. [43] indicated that the high levels of $\Sigma_{9}$ PAEs were observed in dust from developed areas, and the high producing capacity and consumption amount of PAEs in developed cities may influence their geographic distribution. In addition, the levels of PAEs in urban and rural soil have been reported in previous studies, which reflected that the urbanization and industrialization commercial activities and dense population may cause the increased PAE concentrations in soil $[59,60]$. The high level of PAEs in the center of urban areas was probably caused by the densely anthropogenic activities [61].

PAE occurrence in residential dust was mainly derived from the usage of PAE products (such as home building materials, electronic products, cosmetics, and consumer products). Previous studies have proven that phthalate contamination is related to the use of building materials and electronics. The highest concentration of $\Sigma_{16}$ PAEs in the agricultural soils of Guangzhou City was observed at the site close to the largest architecture market of South China, wherein a considerable amount of plastic wastes was discarded [62]. PAEs are also commonly used in consumer products [9], and these chemicals released from PAE products would not degrade because of the nature of the indoor environment and may persist for a long time [63]. The consumption of PAE products in large cities is higher than that in small places, which resulted in the low concentration of PAEs in the country.

\section{Composition profiles of PAEs in indoor dust}

The composition characteristics of PAEs in indoor dust are presented in Fig. 5. The composition of PAEs in residential indoor dust from different geographical areas of China was not different, indicating a similar source of PAEs in the indoor environment. Considering the composition among all geographical regions, DEHP was the most abundant PAE individual in indoor dust from residential buildings, followed by DBP and DIBP, demonstrating proportions of $60.42,28.02$, and $10.51 \%$ of $\Sigma_{8}$ PAEs, respectively. Especially, the contribution of DEHP to the total concentration of PAEs was reached 83.79\% in Northeast China. Kang et al. [41] also illustrated that DBP, DEHP, and DIBP were the predominant compounds in indoor dust around the Pearl River Delta, accounting for $1.72-29.30 \%, 56.00-96.50 \%$, and $0.35-13.40 \%$ to the total PAEs, respectively. Moreover, the predominance of DEHP and DBP was found in other environmental matrices, including soil $[64,65]$, water [16], sediment [16], air [13], and sludge [66]. Considering the low contribution of DMP and DEP, Orecchio et al. (2013) [67] reported that the percentages of the high volatile PAEs (e.g., DMP, DEP) in indoor dust were generally lower than those with low volatility.

The proportions of individual PAEs in the indoor dusts in dormitories were in the order of DEHP $>\mathrm{DBP}>\mathrm{DIB}$ $\mathrm{P}>\mathrm{DNP}>\mathrm{DnOP}>\mathrm{DMP}>\mathrm{DEP}>\mathrm{BBz}$. The cumulative concentration of DEHP, DBP, and DIBP accounted for $99.00 \%$ of $\Sigma_{8}$ PAEs, which was consistent with residences.

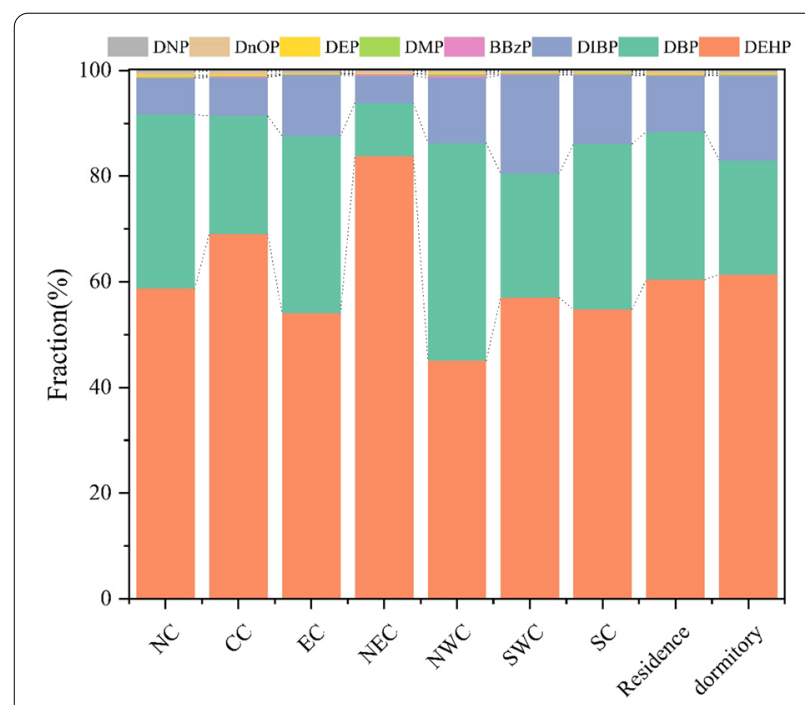

Fig. 5 Composition profiles of PAEs in indoor dusts of residences and dormitories from several regions in China 
The similar pattern of PAE contamination profile in indoor dusts collected from residences and dormitories in China suggested the main sources of PAEs in different indoor dusts were similar.

\section{Human exposure of phthalate esters via indoor dust}

The ADDs of eight measured phthalates via multiple pathways in indoor dusts for children (between the age of 1-6) and adults are shown in Table 1. The results indicated that the total intakes $\Sigma \mathrm{ADD}\left(\mathrm{ADD}_{\text {ing }}+\mathrm{ADD}\right.$ inh $+\mathrm{ADD}_{\text {der }}$ ) of PAEs from indoor dusts for children and adults were $4.38 \times 10^{-4}$ and $7.23 \times 10^{-5} \mathrm{mg} \cdot \mathrm{kg}^{-1} \cdot \mathrm{d}^{-1}$ respectively indicating that children were more susceptible to the PAE intake than the adults. The ADDs of children via ingestion, dermal, and inhalation of indoor dusts were respectively 6.07-, 5.12-, and 2.14-folds higher than those of adults possibly due to the additional hand-to-mouth activities and the differences in selected parameters (such as lower body weights and high ED). Simultaneously, the calculated $\Sigma$ ADD, ADD $_{\text {ing }}$, and $\mathrm{ADD}_{\mathrm{der}}$ of women were respectively approximately $1.17,1.17$, and 1.04 times larger than men. However, the $\mathrm{ADD}_{\text {inh }}$ of women was at a lower level than men, which might be attributed to different physiological

Table 1 Health risk of human exposure to PAEs in indoor dust

\begin{tabular}{|c|c|c|c|c|c|c|c|c|c|c|}
\hline & & $\mathrm{BBzP}$ & DEHP & DMP & DEP & DBP & DnOP & DIBP & DNP & ¿PAEs \\
\hline \multirow[t]{4}{*}{$A D D_{\text {ing }}$} & Children & $5.11 \mathrm{E}-07$ & $2.12 \mathrm{E}-04$ & $6.28 \mathrm{E}-07$ & $6.7 \mathrm{E}-07$ & $9.83 \mathrm{E}-05$ & $1.09 E-06$ & $3.69 E-05$ & $7.72 \mathrm{E}-07$ & $4.36 \mathrm{E}-04$ \\
\hline & Adults & $8.42 \mathrm{E}-08$ & 3.49E-05 & $1.03 \mathrm{E}-07$ & $1.1 \mathrm{E}-07$ & $1.62 \mathrm{E}-05$ & $1.80 \mathrm{E}-07$ & 6.07E-06 & $1.27 \mathrm{E}-07$ & 7.19E-05 \\
\hline & Adult males & $7.75 \mathrm{E}-08$ & $3.21 E-05$ & $9.52 \mathrm{E}-08$ & $1.02 \mathrm{E}-07$ & $1.49 \mathrm{E}-05$ & $1.66 \mathrm{E}-07$ & $5.59 \mathrm{E}-06$ & $1.17 \mathrm{E}-07$ & $6.61 E-05$ \\
\hline & Adult females & $9.10 \mathrm{E}-08$ & 3.77E-05 & $1.12 \mathrm{E}-07$ & $1.19 \mathrm{E}-07$ & $1.75 E-05$ & $1.95 \mathrm{E}-07$ & $6.56 \mathrm{E}-06$ & $1.37 \mathrm{E}-07$ & 7.77E-05 \\
\hline \multirow[t]{4}{*}{$\mathrm{ADD}_{\text {der }}$} & Children & $2.41 \mathrm{E}-09$ & $1.00 \mathrm{E}-06$ & 2.97E-09 & 3.17E-09 & $4.64 \mathrm{E}-07$ & $5.16 \mathrm{E}-09$ & $1.74 \mathrm{E}-07$ & $3.65 E-09$ & $2.06 \mathrm{E}-06$ \\
\hline & Adults & $4.72 \mathrm{E}-10$ & $1.95 E-07$ & $5.79 E-10$ & $6.18 \mathrm{E}-10$ & $9.07 \mathrm{E}-08$ & $1.01 \mathrm{E}-09$ & $3.40 \mathrm{E}-08$ & $7.12 \mathrm{E}-10$ & $4.02 \mathrm{E}-07$ \\
\hline & Adult males & $4.61 \mathrm{E}-10$ & 1.91E-07 & $5.66 \mathrm{E}-10$ & $6.04 \mathrm{E}-10$ & $8.86 \mathrm{E}-08$ & $9.86 \mathrm{E}-10$ & $3.32 \mathrm{E}-08$ & $6.96 \mathrm{E}-10$ & $3.93 E-07$ \\
\hline & Adult females & $4.78 \mathrm{E}-10$ & $1.98 \mathrm{E}-07$ & $5.87 E-10$ & $6.26 \mathrm{E}-10$ & $9.19 \mathrm{E}-08$ & $1.02 \mathrm{E}-09$ & $3.45 E-08$ & $7.22 \mathrm{E}-10$ & $4.08 \mathrm{E}-07$ \\
\hline \multirow[t]{4}{*}{$A D D_{\text {inh }}$} & Children & $4.18 \mathrm{E}-11$ & 1.73E-08 & $5.13 \mathrm{E}-11$ & $5.48 \mathrm{E}-11$ & 8.03E-09 & $8.93 E-11$ & 3.01E-09 & $6.31 \mathrm{E}-11$ & $3.57 \mathrm{E}-08$ \\
\hline & Adults & $1.94 \mathrm{E}-11$ & 8.06E-09 & $2.39 E-11$ & $2.55 E-11$ & $3.74 \mathrm{E}-09$ & $4.16 \mathrm{E}-11$ & $1.40 \mathrm{E}-09$ & $2.94 \mathrm{E}-11$ & $1.66 \mathrm{E}-08$ \\
\hline & Adult males & $2.05 E-11$ & 8.50E-09 & $2.52 \mathrm{E}-11$ & $2.69 \mathrm{E}-11$ & $3.94 \mathrm{E}-09$ & $4.38 \mathrm{E}-11$ & $1.48 \mathrm{E}-09$ & $3.10 E-11$ & $1.75 E-08$ \\
\hline & Adult females & $1.94 \mathrm{E}-11$ & 8.05E-09 & $2.38 \mathrm{E}-11$ & $2.54 \mathrm{E}-11$ & $3.73 \mathrm{E}-09$ & $4.15 E-11$ & $1.40 \mathrm{E}-09$ & $2.93 \mathrm{E}-11$ & $1.66 \mathrm{E}-08$ \\
\hline \multirow[t]{4}{*}{$H Q_{i n g}$} & Children & $2.56 \mathrm{E}-06^{*}$ & $1.06 \mathrm{E}-02^{*}$ & $6.28 \mathrm{E}-08$ & $8.38 \mathrm{E}-07$ & $9.83 \mathrm{E}-04^{*}$ & $2.73 \mathrm{E}-06^{*}$ & & & \\
\hline & Adults & $4.21 \mathrm{E}-07$ & $1.75 \mathrm{E}-03^{*}$ & $1.03 \mathrm{E}-08$ & $1.38 \mathrm{E}-07$ & $1.62 \mathrm{E}-04^{*}$ & $4.50 \mathrm{E}-07$ & & & \\
\hline & Adult males & $3.87 \mathrm{E}-07$ & $1.61 E-03^{*}$ & $9.52 \mathrm{E}-09$ & $1.27 \mathrm{E}-07$ & $1.49 \mathrm{E}-04^{*}$ & $4.14 \mathrm{E}-07$ & & & \\
\hline & Adult females & $4.55 \mathrm{E}-07$ & $1.89 \mathrm{E}-03^{*}$ & $1.12 \mathrm{E}-08$ & $1.49 E-07$ & $1.75 \mathrm{E}-04^{*}$ & 4.87E-07 & & & \\
\hline \multirow{4}{*}{$H Q_{\text {der }}$} & Children & $1.21 \mathrm{E}-08$ & $5.00 \mathrm{E}-05^{*}$ & $2.97 \mathrm{E}-10$ & $3.96 \mathrm{E}-09$ & $4.64 \mathrm{E}-06^{*}$ & $1.29 E-08$ & & & \\
\hline & Adults & $2.36 \mathrm{E}-09$ & $9.77 E-06^{*}$ & $5.79 E-11$ & $7.73 E-10$ & $9.07 \mathrm{E}-07$ & $2.52 \mathrm{E}-09$ & & & \\
\hline & Adult males & $2.31 \mathrm{E}-09$ & $9.55 E-06^{*}$ & $5.66 \mathrm{E}-11$ & $7.55 E-10$ & $8.86 \mathrm{E}-07$ & $2.46 \mathrm{E}-09$ & & & \\
\hline & Adult females & $2.39 E-09$ & $9.90 \mathrm{E}-06^{*}$ & $5.87 \mathrm{E}-11$ & $7.83 E-10$ & $9.19 \mathrm{E}-07$ & $2.55 \mathrm{E}-09$ & & & \\
\hline \multirow[t]{4}{*}{$H Q_{\text {inh }}$} & Children & $2.09 E-10$ & 8.66E-07 & $5.13 E-12$ & $6.85 E-11$ & $8.03 \mathrm{E}-08$ & $2.23 \mathrm{E}-10$ & & & \\
\hline & Adults & $9.72 \mathrm{E}-11$ & 4.03E-07 & $2.39 E-12$ & $3.19 \mathrm{E}-11$ & $3.74 \mathrm{E}-08$ & $1.04 \mathrm{E}-10$ & & & \\
\hline & Adult males & $1.03 E-10$ & $4.25 E-07$ & $2.52 \mathrm{E}-12$ & $3.36 \mathrm{E}-11$ & $3.94 \mathrm{E}-08$ & $1.10 E-10$ & & & \\
\hline & Adult females & $9.71 \mathrm{E}-11$ & $4.02 \mathrm{E}-07$ & $2.38 \mathrm{E}-12$ & $3.18 \mathrm{E}-11$ & $3.73 \mathrm{E}-08$ & $1.04 \mathrm{E}-10$ & & & \\
\hline \multirow[t]{4}{*}{$\mathrm{HI}$} & Children & $2.57 \mathrm{E}-06^{*}$ & $1.06 \mathrm{E}-02^{*}$ & $6.31 \mathrm{E}-08$ & $8.42 \mathrm{E}-07$ & $9.88 \mathrm{E}-04^{*}$ & $2.75 \mathrm{E}-06^{*}$ & & & \\
\hline & Adults & $4.24 \mathrm{E}-07$ & $1.76 \mathrm{E}-03^{*}$ & $1.04 \mathrm{E}-08$ & $1.39 \mathrm{E}-07$ & $1.63 \mathrm{E}-04^{*}$ & $4.53 \mathrm{E}-07$ & & & \\
\hline & Adult males & $3.90 \mathrm{E}-07$ & $1.62 \mathrm{E}-03^{*}$ & $9.58 \mathrm{E}-09$ & $1.28 \mathrm{E}-07$ & $1.50 E-04^{*}$ & $4.17 \mathrm{E}-07$ & & & \\
\hline & Adult females & $4.58 \mathrm{E}-07$ & $1.90 \mathrm{E}-03^{*}$ & $1.12 \mathrm{E}-08$ & $1.50 \mathrm{E}-07$ & $1.76 \mathrm{E}-04^{*}$ & $4.89 \mathrm{E}-07$ & & & \\
\hline \multirow[t]{3}{*}{ LADD } & Adults & $6.84 \mathrm{E}-08$ & $2.83 \mathrm{E}-05$ & & & & & & & \\
\hline & Adult males & $6.84 \mathrm{E}-08$ & $2.84 \mathrm{E}-05$ & & & & & & & \\
\hline & Adult females & $6.82 \mathrm{E}-08$ & $2.83 E-05$ & & & & & & & \\
\hline \multirow[t]{3}{*}{$C R$} & Adults & $1.30 \mathrm{E}-10$ & $3.97 \mathrm{E}-07$ & & & & & & & \\
\hline & Adult males & $1.30 \mathrm{E}-10$ & $3.97 \mathrm{E}-07$ & & & & & & & \\
\hline & Adult females & $1.30 \mathrm{E}-10$ & $3.96 \mathrm{E}-07$ & & & & & & & \\
\hline
\end{tabular}


characteristics, living habits, and other parameters. Dust ingestion was the main pathway of human PAE exposure from indoor dusts. The ADDs of PAEs for children and adults through dust ingestion were 2-4 orders of magnitude higher than those through dust inhalation and dermal adsorption. Similar results were also reported by other studies [27, 43].

The HI of noncancer risks for children, adult female, and adult male exposure to individual PAEs in the indoor dusts was in the decreasing order of DEHP $>$ DBP $>$ DnO $\mathrm{P}>\mathrm{BBzP}>\mathrm{DEP}>\mathrm{DMP}$. The HI values of DEP and DMP from indoor dust for children and adults were all within the acceptable level. However, the HI values of DEHP and DBP for all age groups were 3-4 orders of magnitude higher than $1 \times 10^{-6}$. This finding indicates the noncancer risk to children and adults from DEHP and DBP exposure through indoor dust. Moreover, the noncancer risk for PAE exposure in children in indoor dust was larger than that in adults, and the HI for children was 6.07 times larger than adults. Simultaneously, the HI values of $\mathrm{BBzP}$ and DnOP to children also exceeded $1 \times 10^{-6}$ with the values of $2.57 \times 10^{-6}$ and $2.75 \times 10^{-6}$, respectively. In addition, women were found to be at heightened risks than men (Table 1). The carcinogenic risks of DEHP and $\mathrm{BBzP}$ in indoor dusts for adults via three exposure routes were $3.97 \times 10^{-7}$ and $1.30 \times 10^{-10}$, respectively. Carcinogenic risk profiles for adult males $\left(\mathrm{CR}_{\mathrm{DEHP}}\right.$ : $3.97 \times 10^{-7}$; $\left.\mathrm{CR}_{\mathrm{BBz}}: 1.30 \times 10^{-10}\right)$ and females $\left(\mathrm{CR}_{\mathrm{DEHP}}: 3.96 \times 10^{-7}\right.$; $\left.\mathrm{CR}_{\mathrm{BBz}}: 1.30 \times 10^{-10}\right)$ were similar. These profiles were all below the threshold value $\left(1 \times 10^{-6}\right)$, indicating that the carcinogenic risk of human exposure to DEHP and BBzP in indoor dusts was relatively low or negligible.

\section{Possible sources of PAEs in indoor dust Source apportionment by PCA model}

PCA and Pearson correlation analysis were performed to investigate the possible sources of PAEs in indoor dust (Fig. 6, Additional file 1: Figures. S3 and S4). The first three principal components (PC1-PC3) with an eigenvalue $>1.0$ were extracted for indoor dusts in residences. PC1 explained $33.50 \%$ of the total variance with loading of 0.97 and 0.85 for DIBP and DMP, respectively. The results were in agreement with the Pearson correlation analysis in the residential dust, which inferred a significant correlation between DMP and DIBP (Fig. 6), indicating possible sharing of similar sources. PC 2 accounted for $25.82 \%$ of the total phthalate esters in these samples and was dominated by low molecular PAEs with high loading for DEHP (0.90), BBzP (0.69), and DNP (0.75). As shown in Fig. 6, DEHP was significantly correlated with $\mathrm{BBzP}$ and DNP, suggesting the possibility of similar sources or emission behaviors. PCA suggested high loading of DBP (0.92) and DEP (0.86) on PC3, which

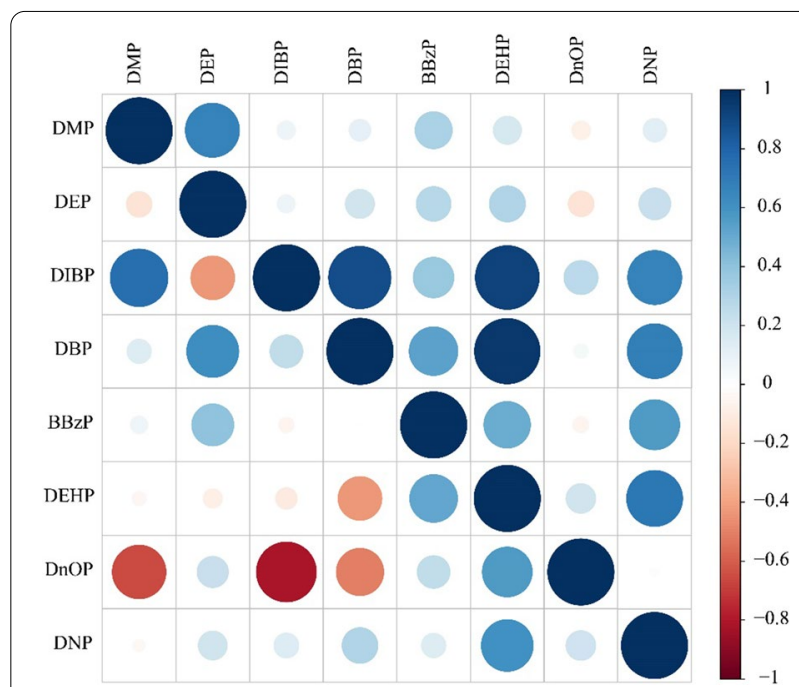

Fig. 6 Correlation analysis of PAEs of indoor dust. The bottom left corner is the correlation analysis of phthalates in indoor dust from residences. The top right corner is the correlation analysis of phthalates in indoor dust from dormitories

contributed as high as $23.39 \%$ to the total variance. Significant correlations were found between DBP and DEP (Fig. 6).

PAEs were used in a wide range of applications, and individual PAE might have multiple uses. High molecular weight PAEs, such as DEHP, DnOP, and BBzP, have been widely used as plasticizers in the polymer industry to improve flexibility, workability, and general handling properties $[1,68,69]$. BBzP and DnOP are also used in construction materials and home furniture, such as wallpapers, vinyl flooring, adhesives, and synthetic leather $[1,68]$. PAEs with low molecular weights, such as DMP, DBP, and DEP, are mainly used in cosmetics and personal care products. In addition, DBP and DIBP are used in applications of plasticizers and personal care products [69]. DBP is also used in special adhesive formulations, cellulose esters, and epoxy resins $[1,70]$. Therefore, DMP and DIBP in PC1 and DBP and DEP in PC3 were mainly related to cosmetics and personal care products and plasticizers. DEHP, BBzP, DnOP, and DNP in PC2 were mainly associated with the use of plasticizers, construction materials, and home furniture.

For indoor dusts in dormitories, the two extracted principal components explained 48.12 and $22.31 \%$ of the total variation (Additional file 1: Figure S4). The elements of the first factor corresponded to those for indoor dust from residences. DBP, DIBP, DNP, DEHP, and BBzP were significantly correlated with each other $(p<0.01$ or $\mathrm{p}<0.05)$. DEP and DMP concentrations were positively correlated $(r=0.664 ; p<0.05)$ (Fig. 6). The second factor was loaded on DMP and DEP, which may also be related 
to the release from cosmetics, personal care products, and surface coating materials [25].

\section{Source apportionment by PMF model}

Two datasets were imported to the PMF 5.0 model in this study, and potential sources of PAEs in residences and dormitories were identified by the PMF model as shown in Fig. 7. The theory and formulas of the PMF and the rationality of the research results are stated in the supplementary material. Three sources for indoor dusts in residences were chosen as the optimal number for the PMF model and were comparable to those characterized by the PCA model with some differences. Factor 1 was responsible for $41.21 \%$ of the total variance and dominated by DIBP (83.64\%), DBP (81.24\%), DEHP (63.06\%), and DNP (66.33\%), which was associated with plasticizers employed in multifarious plastic products. Factor 2 accounted for $41.80 \%$ of the variance and obtained high concentrations for BBzP (79.82\%) and DnOP (88.87\%).
Meanwhile, contributions to other PAEs were relatively low, and a large number of building materials and decorated furniture possibly contributed to this source. The third factor explained $17.52 \%$ of the variance and had high loads on DEP (87.70\%) and DMP (61.52\%), which was mainly linked to the cosmetics and personal care products.

Two sources for dormitories were chosen as the optimal number for the PMF model. Source profiles for PAEs obtained from the PMF model are displayed in Fig. 7b. The source analysis result was consistent with that obtained by the PCA model. The contributions to the $\Sigma$ PAEs of the two sources were F2 (60.38\%) and F1 (36.92\%). DMP (70.90\%) and DEP (54.59\%) were prominent in Factor 1, which is interpreted as the cosmetics and personal care products sources. For Factor 2, DBP (64.79\%), DIBP (50.77\%), DEHP (80.42\%), BBzP (60.48\%), DnOP (88.09\%), and DNP (87.96\%) obtained high weighting. Therefore, the second source denoted the joint

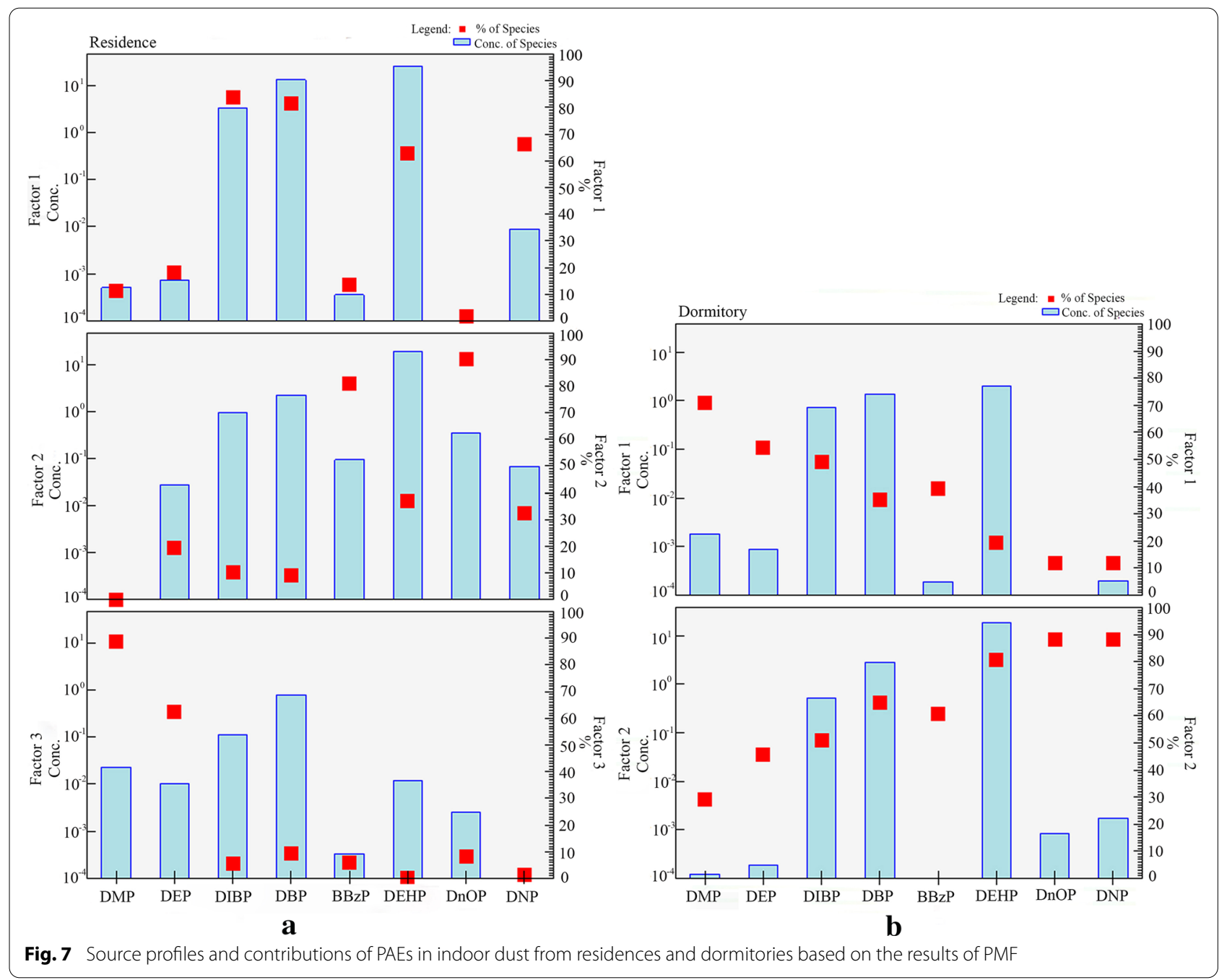


contributions of plasticizers, furnishings, and construction materials.

The difference between source profile in dust in residences and dormitories was possibly related to the usage patterns and the dwelling characteristics. For example, high population density might cause a high contribution of personal care product sources in dormitories. Meanwhile, the use of additional household appliances, decoration materials, and furnishings in residential buildings might lead to the higher source contributions of the plasticizers and furnishings in residences compared with dormitories.

The fitting results were determined by linear regression between the predicted $\Sigma_{8} \mathrm{PAE}$ concentration and the observed concentration. The fitting plots showed that the concentration predicted by the two models both fit well the observed concentration of PAEs in dormitories and residences, respectively ( $R^{2}$ range from 0.8197 to 0.8662) (Fig. 8). Overall, the PMF model (slopes were 0.9822 and 0.8869 for dormitory and residence, respectively) performed better with the slopes closing to " 1 " of the regression equations compared with the PCA model (slopes were 0.9339 and 0.8096 for dormitory and residence, respectively). The $\Sigma_{8} \mathrm{PAE}$ concentration modeled by the PCA and PMF models presented good correlations. As shown in Additional file 1: Figure S5, $R^{2}$ values were 0.8884 and 0.8060 , the intercepts were 16.2120 and 1.6795 , and slopes both approached unity. The comparison of the results between the two models based on the source profiles demonstrates considerable similarities between the two models, but some differences existed in source contributions. As mentioned above, $97.29 \%$ of the $\Sigma_{8}$ PAEs concentrations in dormitories were explained by the PMF model. The $\Sigma_{8} \mathrm{PAE}$ concentrations in residences

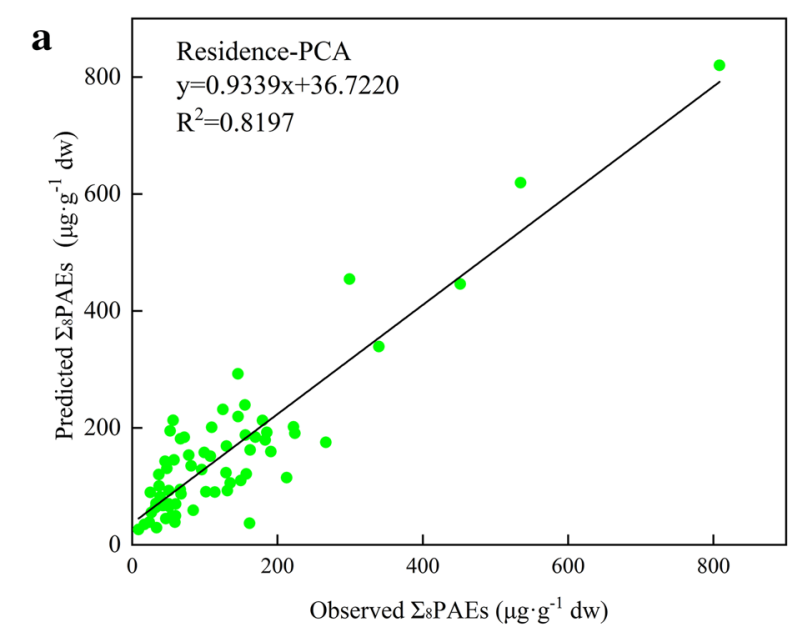

b

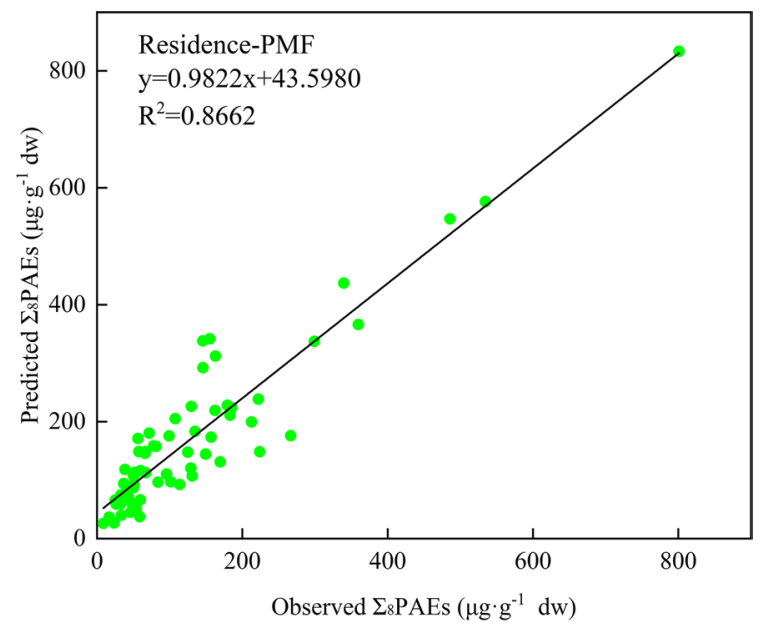

c

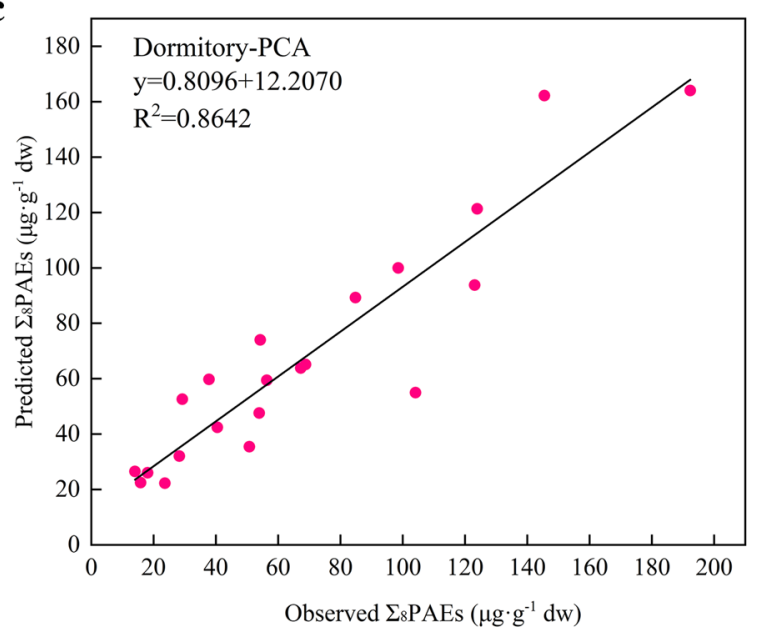

d

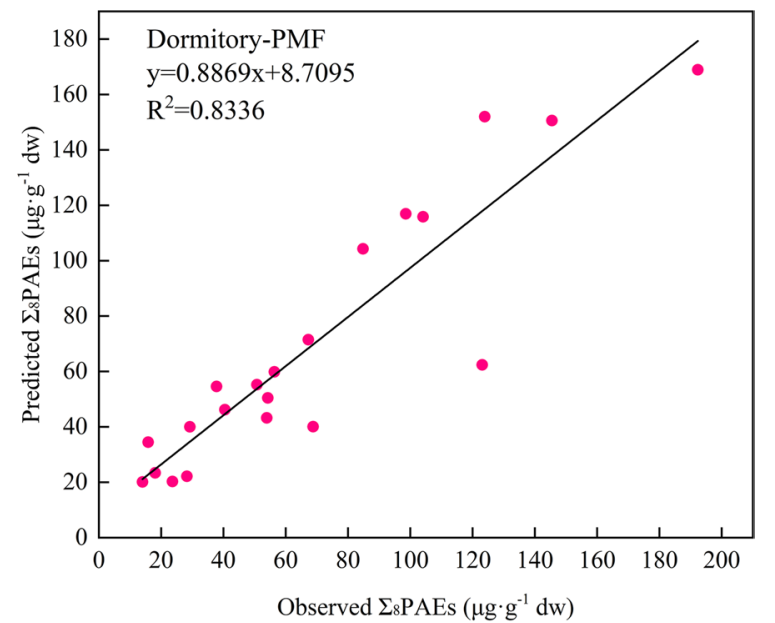

Fig. 8 Model fit of the observed-versus-predicted $\Sigma_{8}$ PAE concentration $\left(\mu \mathrm{g} \cdot \mathrm{g}^{-1}\right)$ from PCA and PMF 
were slightly overestimated by the PMF model with $100.54 \%$. However, the $\Sigma_{8} \mathrm{PAE}$ concentrations in residences and dormitories were all underestimated by the PCA model with 81.70 and $70.43 \%$, respectively. Overall, the results obtained by PMF provided practical and physical meanings. Multiple models should be conducted to reduce the weaknesses of individual approaches to obtain compelling results in future studies.

\section{Conclusions}

Eight PAEs, including DEP, DMP, DIBP, DBP, BBzP, DEHP, DnOP, and DNP, were detected in indoor dusts from several areas in China. Predominant contaminants in the indoor dusts were DBP, DEHP, and DIBP. The highest concentration of $\Sigma_{8}$ PAEs in indoor dust was found in Northeast China and decreased in the order of the Northwest, East China, North China, Central China, South China, and Southwest China. The median concentrations of PAEs in residential buildings were often higher than those in dormitories and the differences in source profiles between the two indoor environments. This finding suggests that the usage pattern of these chemicals was different between residences and dormitories in China. The highest PAE concentration was observed in the provincial capital, followed by nonprovincial city and country. Emissions of cosmetics and personal care products, plasticizers, and household building materials may explain the sources of PAEs in the indoor dusts. The ingestion of indoor dusts was the major pathway of human exposure to PAEs. When compared with adults, children face considerable health risks, and women are more threatened than men. Exposure to DBP and DEHP in indoor environments might cause notable noncancer risks for humans. In addition, the hazard indexes of BBzP and DnOP indicated their noncancer risk to children. The carcinogenic risk of human exposure to DEHP and BBzP in the indoor dusts was negligible. Additional attention should be provided to indoor dusts and measures should be taken to decrease daily PAE exposure of humans.

\section{Supplementary Information}

The online version contains supplementary material available at https://doi. org/10.1186/s12302-021-00457-3.

Additional file 1. Method of positive matrix factorization model (PMF) Additional tables and figures.

\section{Abbreviations}

PAEs: Phthalate esters; DIBP: Di-iso-butyl phthalate; DBP: Di-n-butyl phthalate; BBzP: Benzyl butyl phthalate; DMP: Dimethyl phthalate; DEP: Diethyl phthalate; DEHP: Di(2-ethylhexyl) phthalate; DnOP: Di-n-octyl phthalate; BBzP: Benzyl butyl phthalate; DHXP: Di-n-hexyl phosphoric acid POPs: persistent organic pollutants; DI: Daily intake; PCA: Principal component analysis; PMF: Positive matrix factorization; ADD: The average daily dosage; $I R_{\text {ingestion: }}$ The dust ingestion rate; $I R_{\text {inhalation: }}$ The dust inhalation rate; $S A$ : The dermal exposure area;
ABF: The dermal adsorption fraction; AF: The dermal adherence factor for dust; BW: Body weight; AT: The averaging time; ED: The exposure duration; EF: The exposure frequency; CF: The conversion factor; PEF: The particle emission factor; HQ: Hazard quotient; HI: Hazard index; RfD: The reference dose; LADD: The lifetime average daily exposure doses; CR: Carcinogenic risk; CSF: The cancer

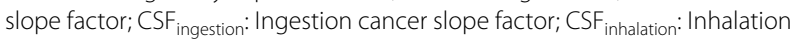
cancer slope factor; $\mathbb{R}_{\text {dermal }}$ : Dermal adsorption cancer slope factor; LOD: Limit of detection; LOQ: Limit of quantification; S/N: Signal/noise ratios.

\section{Acknowledgements}

Not applicable.

\section{Authors' contributions}

$\mathrm{XL}, \mathrm{WP}$ and CS were involved in the investigation, experiments and manuscript writing. JL, SW and WX were involved in the data curation, investigation and validation. CS was responsible for the conceptualization, study design, writing-review and editing, correction and supervision. JX contributed to the conceptualization, review and editing and supervision. All authors read and approved the final manuscript.

\section{Funding}

This work was supported by the National Key Research and Development Program of China (No. 2019YFC1803401), and the second Tibetan Plateau Scientific Expedition and Research Program (STEP) (Grant No. 2019QZKK0608).

\section{Availability of data and materials}

The datasets used and analyzed during the current study are available from the corresponding author on reasonable request.

\section{Ethics approval and consent to participate}

Not applicable.

\section{Consent for publication \\ Not applicable.}

\section{Competing interests}

The authors declare that they have no competing interests.

\section{Author details}

${ }^{1}$ State Key Laboratory of Environmental Criteria and Risk Assessment, Chinese Research Academy of Environmental Sciences, Beijing 100012, China. ${ }^{2}$ State Environmental Protection Key Laboratory of Ecological Effect and Risk Assessment of Chemicals, Chinese Research Academy of Environmental Sciences, Beijing 100012, China. ${ }^{3}$ Center for Environmental Health Risk Assessment and Research, Chinese Research Academy of Environmental Sciences, Beijing 100012, China.

Received: 27 November 2020 Accepted: 23 January 2021

Published online: 12 February 2021

\section{References}

1. Abdel daiem MM, Rivera-Utrilla J, Ocampo-Pérez R, Méndez-Díaz JD, Sánchez-Polo M (2012) Environmental impact of phthalic acid esters and their removal from water and sediments by different technologies-a review. J Environ Manag 109:164-178

2. Fu J, Pan F, Song S, Zhang LR, Luo Y, Chen W, Liang Y (2012) Biodegradation of phthalic acid esters in sewage sludge by composting with pig manure and rice straw. Environ Earth Sci 68(8):2289-2299

3. Wang L, Gong M, Xu Y, Zhang Y (2017) Phthalates in dust collected from various indoor environments in Beijing, China and resulting non-dietary human exposure. Build Environ 124:315-322

4. Wang L, Wu Z, Gong M, Xu Y, Zhang Y (2020) Non-dietary exposure to phthalates for prE-school children in kindergarten in Beijing, China. Build Environ. https://doi.org/10.1016/j.buildenv.2019.106438

5. Wang B, Li J, Qi L, Zhang W, Chen W, Guo G, Huo E (2019) Research progress of new environmental plasticizers. Henan Chemical Industry 36(03):7-10

6. 2019 Plastic additives production and application technology information exchange Conference held in Xi'an. Plastics Additives 2019(06): 56. 
7. Kolarik B, Bornehag CG, Naydenov K, Sundell J, Stavova P, Nielsen OF (2008) The concentrations of phthalates in settled dust in Bulgarian homes in relation to building characteristic and cleaning habits in the family. Atmos Environ 42(37):8553-8559

8. Gómez-Hens A, Aguilar-Caballos M (2003) Social and economic interest in the control of phthalic acid esters. TrAC Trends Anal Chem 22(11):847-857

9. Luongo G, Ostman C (2016) Organophosphate and phthalate esters in settled dust from apartment buildings in Stockholm. Indoor Air 26(3):414-425

10. Shi W, Hu X, Zhang F, Hu G, Hao Y, Zhang X, Liu H, Wei S, Wang X, Giesy JP, Yu H (2012) Occurrence of thyroid hormone activities in drinking water from eastern China: contributions of phthalate esters. Environ Sci Technol 46(3):1811-1818

11. Huang G, Sun J, Chen Z, Chen X, Jing J, Liu J (2012) Levels and sources of phthalate esters in shallow groundwater and surface water of dongguan city, south china. Geochem J 46(5):421-428

12. Chen M, Jiang J, Gan Z, Yan Y, Ding S, Su S, Bao X (2019) Grain size distribution and exposure evaluation of organophosphorus and brominated flame retardants in indoor and outdoor dust and PM10 from Chengdu, China. J Hazard Mater 365:280-288

13. Kong S, Ji Y, Liu L, Chen L, Zhao X, Wang J, Bai Z, Sun Z (2013) Spatial and temporal variation of phthalic acid esters (PAEs) in atmospheric PM10 and PM2.5 and the influence of ambient temperature in Tianjin, China. Atmos Environ 74:199-208

14. Maceira A, Borrull F, Marce RM (2019) Occurrence of plastic additives in outdoor air particulate matters from two industrial parks of Tarragona, Spain: human inhalation intake risk assessment. J Hazard Mater 373:649-659

15. Wang X, Tao W, Xu Y, Feng J, Wang F (2014) Indoor phthalate concentration and exposure in residential and office buildings in Xi'an, China. Atmos Environ 87:146-152

16. Chen H, Mao W, Shen Y, Feng W, Mao G, Zhao T, Yang L, Yang L, Meng C, Li Y, Wu X (2019) Distribution, source, and environmental risk assessment of phthalate esters (PAEs) in water, suspended particulate matter, and sediment of a typical Yangtze River Delta City China. Environ Sci Pollut Res 26(24):24609-24619

17. Liu H, Liang H, Liang Y, Zhang D, Wang C, Cai H, Shvartsev SL (2010) Distribution of phthalate esters in alluvial sediment: a case study at JiangHan Plain, Central China. Chemosphere 78(4):382-388

18. Kong S, Ji Y, Liu L, Chen L, Zhao X, Wang J, Bai Z, Sun Z (2012) Diversities of phthalate esters in suburban agricultural soils and wasteland soil appeared with urbanization in China. Environ Pollut 170:161-168

19. Wang $H$, Liang $H$, Gao DW (2017) Occurrence and risk assessment of phthalate esters (PAEs) in agricultural soils of the Sanjiang Plain, northeast China. Environ Sci Pollut Res 24(24):19723-19732

20. Guo Y, Zhang Z, Liu L, Li Y, Ren N, Kannan K (2012) Occurrence and profiles of phthalates in foodstuffs from China and their implications for human exposure. J Agric Food Chem 60(27):6913-6919

21. He MJ, Lu JF, Ma JY, Wang H, Du XF (2018) Organophosphate esters and phthalate esters in human hair from rural and urban areas, Chongqing, China: concentrations, composition profiles and sources in comparison to street dust. Environ Pollut 237:143-153

22. Yao Y, Chen D, Wu Y, Zhou L, Cheng J, Li Y, Lu S, Yuan G, Liu G (2019) Urinary phthalate metabolites in primary school starters in Pearl River Delta, China: occurrences, risks and possible sources. Environ Res 179(Pt B): 108853

23. Wang L, Zhang W, Tao W, Wang L, Shi X, Lu X (2017) Investigating into composition, distribution, sources and health risk of phthalic acid esters in street dust of Xi'an City, Northwest China. Environ Geochem Health 39(4):865-877

24. Bornehag CG, Carlstedt F, Jonsson BA, Lindh CH, Jensen TK, Bodin A, Jonsson C, Janson S, Swan SH (2015) Prenatal phthalate exposures and anogenital distance in Swedish boys. Environ Sci Pollut Res 123(1):101-107

25. Koch HM, Wittassek M, Bruning T, Angerer J, Heudorf U (2011) Exposure to phthalates in 5-6 years old primary school starters in Germany-a human biomonitoring study and a cumulative risk assessment. Int J Hyg Environ Health 214(3):188-195

26. Wang H, Zhou Y, Tang C, He Y, Wu J, Chen Y, Jiang Q (2013) Urinary phthalate metabolites are associated with body mass index and waist circumference in Chinese school children. PLoS ONE 8(2):e56800
27. Wang L, Liu M, Tao W, Zhang W, Wang L, Shi X, Lu X, Li X (2018) Pollution characteristics and health risk assessment of phthalate esters in urban soil in the typical semi-arid city of Xi'an, Northwest China. Chemosphere 191:467-476

28. US EPA (2011) Toxic and priority pollutants under the Clean Water Act http://water.epa.gov/scitech/methods/cwa/pollutants.cfm. Accessed 6 Feb 2021

29. Net S, Sempere R, Delmont A, Paluselli A, Ouddane B (2015) Occurrence, fate, behavior and ecotoxicological state of phthalates in different environmental matrices. Environ Sci Technol 49(7):4019-4035

30. Yang HJ, Xie WJ, Liu Q, Liu JT, Yu HW, Lu ZH (2013) Distribution of phthalate esters in topsoil: a case study in the Yellow River Delta, China. Environ Monit Assess 185(10):8489-8500

31. Wei GL, Li DQ, Zhuo MN, Liao YS, Xie ZY, Guo TL, Li JJ, Zhang SY, Liang ZQ (2015) Organophosphorus flame retardants and plasticizers: sources, occurrence, toxicity and human exposure. Environ Pollut 196:29-46

32. Guo Y, Kannan K (2011) Comparative assessment of human exposure to phthalate esters from house dust in China and the United States. Environ Sci Technol 45(8):3788-3794

33. Becker K, Goen T, Seiwert M, Conrad A, Pick-Fuss H, Muller J, Wittassek M, Schulz C, Kolossa-Gehring M (2009) GerES IV: phthalate metabolites and bisphenol A in urine of German children. Int J Hyg Environ Health 212(6):685-692

34. Fromme H, LahrzT, Piloty M, Gebhart H, Oddoy A, Ruden H (2004) Occurrence of phthalates and musk fragrances in indoor air and dust from apartments and kindergartens in Berlin (Germany). Indoor Air 14(3):188-195

35. Langer S, Weschler CJ, Fischer A, Bekö G, Toftum J, Clausen G (2010) Phthalate and PAH concentrations in dust collected from Danish homes and daycare centers. Atmos Environ 44(19):2294-2301

36. Rakkestad KE, Dye CJ, Yttri KE, Holme JA, Hongslo JK, Schwarze PE, Becher $R$ (2007) Phthalate levels in Norwegian indoor air related to particle size fraction. J Environ Monit 9(12):1419-1425

37. Bornehag CG, Lundgren B, Weschler CJ, Sigsgaard T, Hagerhed-Engman L, Sundell J (2005) Phthalates in indoor dust and their association with building characteristics. Environ Health Perspect 113(10):1399-1404

38. Ait Bamai Y, Araki A, Kawai T, Tsuboi T, Saito I, Yoshioka E, Kanazawa A, Tajima S, Shi C, Tamakoshi A, Kishi R (2014) Associations of phthalate concentrations in floor dust and multi-surface dust with the interior materials in Japanese dwellings. Sci Total Environ 468-469:147-157

39. Zhang Q, Lu XM, Zhang XL, Sun YG, Zhu DM, Wang BL, Zhao RZ, Zhang ZD (2013) Levels of phthalate esters in settled house dust from urban dwellings with young children in Nanjing, China. Atmos Environ 69:258-264

40. Li Y, Lu J, Yin X, Liu Z, Tong Y, Zhou L (2019) Indoor phthalate concentrations in residences in Shihezi, China: implications for preschool children's exposure and risk assessment. Environ Sci Pollut Res 26(19):19785-19794

41. Kang Y, Man YB, Cheung KC, Wong MH (2012) Risk assessment of human exposure to bioaccessible phthalate esters via indoor dust around the pearl river delta. Environ Sci Technol 46(15):8422-8430

42. Bu Z, Zhang Y, Mmereki D, Yu W, Li B (2016) Indoor phthalate concentration in residential apartments in Chongqing, China: implications for preschool children's exposure and risk assessment. Atmos Environ 127:34-45

43. Zhu Q, Jia J, Zhang K, Zhang H, Liao C, Jiang G (2019) Phthalate esters in indoor dust from several regions, China and their implications for human exposure. Sci Total Environ 652:1187-1194

44. ISO 13913-2014 (2014) Soil quality-Determination of selected phthalates using capillary gas chromatography with mass spectrometric detection (GC/MS). https://www.iso.org/standard/54342.html. Accessed 6 Feb 2021

45. Zhang Y, Guo CS, Xu J, Tian YZ, Shi GL, Feng YC (2012) Potential source contributions and risk assessment of PAHs in sediments from Taihu Lake, China: Comparison of three receptor models. Water Res 46:3065-3073

46. Xu J, Tian YZ, Zhang Y, Guo CS, Shi GL, Zhang CY, Feng YC (2013) Source apportionment of perfluorinated compounds (PFCs) in sediments: Using three multivariate factor analysis receptor models. J Hazard Mater 260:483-488

47. Xu J, Shi GL, Guo CS, Wang HT, Tian YZ, Huangfu YQ, Zhang Y, Feng YC, Xu J (2018) A new method to quantify the health risks from sources of perfluoroalkyl substances, combined with positive matrix factorization and risk assessment models. Environ Toxicol Chem 37:107-115 
48. U.S. EPA. Exposure Factors Handbook 2011 Edition (Final Report) (2011) U.S. Environmental Protection Agency, Washington, DC, EPA/600/R09/052F. https://cfpub.epa.gov/ncea/risk/recordisplay.cfm?deid=23625 2. Accessed 6 Feb 2021

49. Basaran B, Soylu GN, Yilmaz Civan M (2020) Concentration of phthalate esters in indoor and outdoor dust in Kocaeli, Turkey: implications for human exposure and risk. Environ Sci Pollut Res 27(2):1808-1824

50. Wang J, Chen G, Christie P, Zhang M, Luo Y, Teng Y (2015) Occurrence and risk assessment of phthalate esters (PAEs) in vegetables and soils of suburban plastic film greenhouses. Sci Total Environ 523:129-137

51. Wang P, Wang SL, Fan CQ (2008) Atmospheric distribution of particulatEand gas-phase phthalic esters (PAEs) in a Metropolitan City, Nanjing, East China. Chemosphere 72(10):1567-1572

52. Bergh C, Torgrip R, Emenius G, Ostman C (2011) Organophosphate and phthalate esters in air and settled dust - a multi-location indoor study. Indoor Air 21(1):67-76

53. Mercier F, Gilles E, Saramito G, Glorennec P, Le Bot B (2014) A multiresidue method for the simultaneous analysis in indoor dust of several classes of semi-volatile organic compounds by pressurized liquid extraction and gas chromatography/tandem mass spectrometry. J Chromatogr A 1336:101-111

54. Albar HMSA, Ali N, Shahzad K, Ismail IMI, Rashid MI, Wang W, Ali LN, Eqani SAMAS (2017) Phthalate esters in settled dust of different indoor microenvironments; source of non-dietary human exposure. Microchem J 132:227-232

55. Bi X, Yuan S, Pan X, Winstead C, Wang Q (2015) Comparison, association, and risk assessment of phthalates in floor dust at different indoor environments in Delaware, USA. J Environ Sci Health Part A 50(14):1428-1439

56. Gaspar FW, Castorina R, Maddalena RL, Nishioka MG, McKone TE, Bradman A (2014) Phthalate Exposure and Risk Assessment in California Child Care Facilities. Environ Sci Technol 48(13):7593-7601

57. Kubwabo C, Rasmussen PE, Fan X, Kosarac I, Wu F, Zidek A, Kuchta SL (2013) Analysis of selected phthalates in Canadian indoor dust collected using household vacuum and standardized sampling techniques. Indoor Air 23(6):506-514

58. Christia C, Poma G, Harrad S, de Wit CA, Sjostrom Y, Leonards P, Lamoree M, Covaci A (2019) Occurrence of legacy and alternative plasticizers in indoor dust from various EU countries and implications for human exposure via dust ingestion and dermal absorption. Environ Res 171:204-212

59. Huo CY, Liu LY, Zhang ZF, Ma WL, Song WW, Li HL, Li WL, Kannan K, Wu YK, Han YM, Peng ZX, Li YF (2016) Phthalate esters in indoor window films in a Northeastern Chinese urban center: film growth and implications for human exposure. Environ Sci Technol 50(14):7743-7751
60. Lu H, Mo CH, Zhao HM, Xiang L, Katsoyiannis A, Li YW, Cai QY, Wong MH (2018) Soil contamination and sources of phthalates and its health risk in China: A review. Environ Res 164:417-429

61. Li XH, Ma LL, Liu XF, Fu S, Cheng HX, Xu XB (2006) Phthalate ester pollution in urban soil of Beijing, People's Republic of China. Bull Environ Contam Toxicol 77(2):252-259

62. Zeng F, Cui K, Xie Z, Wu L, Liu M, Sun G, Lin Y, Luo D, Zeng Z (2008) Phthalate esters (PAEs): emerging organic contaminants in agricultural soils in peri-urban areas around Guangzhou, China. Environ Pollut 156(2):425-434

63. Fan X, Kubwabo C, Rasmussen PE, Wu F (2014) Simultaneous determination of thirteen organophosphate esters in settled indoor house dust and a comparison between two sampling techniques. Sci Total Environ 491-492:80-86

64. Niu L, Xu Y, Xu C, Yun L, Liu W (2014) Status of phthalate esters contamination in agricultural soils across China and associated health risks. Environ Pollut 195:16-23

65. Xia X, Yang L, Bu Q, Liu R (2011) Levels, distribution, and health risk of phthalate esters in urban soils of Beijing, China. J Environ Qual 40(5):1643-1651

66. Cai QY, Mo CH, Wu QT, Zeng QY, Katsoyiannis A (2007) Occurrence of organic contaminants in sewage sludges from eleven wastewater treatment plants China. Chemosphere 68(9):1751-1762

67. Orecchio S, Indelicato R, Barreca S (2013) The distribution of phthalate esters in indoor dust of Palermo (Italy). Environ Geochem Health 35(5):613-624

68. Gong M, Zhang Y, Weschler CJ (2014) Measurement of phthalates in skin wipes: estimating exposure from dermal absorption. Environ Sci Technol 48(13):7428-7435

69. Lanciotti R, Gianotti A, Patrignani F, Belletti N, Guerzoni ME, Gardini F (2004) Use of natural aroma compounds to improve shelf-life and safety of minimally processed fruits. Trends Food Sci Technol 15(3-4):201-208

70. IARC (International Agency for Research on Cancer) (2000) Monographs on the evaluation of carcinogenic risks to humans some industrial chemicals, vol 77. International Agency for Research on Cancer, Lyon

\section{Publisher's Note}

Springer Nature remains neutral with regard to jurisdictional claims in published maps and institutional affiliations.

\section{Submit your manuscript to a SpringerOpen ${ }^{\circ}$ journal and benefit from:}

- Convenient online submission

- Rigorous peer review

- Open access: articles freely available online

- High visibility within the field

- Retaining the copyright to your article

Submit your next manuscript at $\boldsymbol{\nabla}$ springeropen.com 